\title{
Genetic counseling and testing practices for late-onset neurodegenerative disease: a systematic review
}

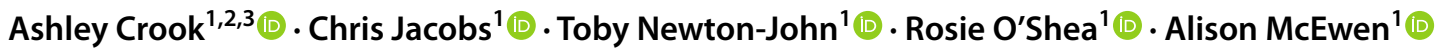

Received: 9 December 2020 / Revised: 10 February 2021 / Accepted: 10 February 2021 / Published online: 1 March 2021

(c) Springer-Verlag GmbH, DE part of Springer Nature 2021

\begin{abstract}
Objective To understand contemporary genetic counseling and testing practices for late-onset neurodegenerative diseases (LONDs), and identify whether practices address the internationally accepted goals of genetic counseling: interpretation, counseling, education, and support.

Methods Four databases were systematically searched for articles published from 2009 to 2020 . Peer-reviewed research articles in English that reported research and clinical genetic counseling and testing practices for LONDs were included. A narrative synthesis was conducted to describe different practices and map genetic counseling activities to the goals. Risk of bias was assessed using the Qualsyst tool. The protocol was registered with PROSPERO (CRD42019121421).

Results Sixty-one studies from 68 papers were included. Most papers focused on predictive testing (58/68) and Huntington's disease (41/68). There was variation between papers in study design, study population, outcomes, interventions, and settings. Although there were commonalities, novel and inconsistent genetic counseling practices were identified. Eighteen papers addressed all four goals of genetic counseling.

Conclusion Contemporary genetic counseling and testing practices for LONDs are varied and informed by regional differences and the presence of different health providers. A flexible, multidisciplinary, client- and family-centered care continues to emerge. As genetic testing becomes a routine part of care for patients (and their relatives), health providers must balance their limited time and resources with ensuring clients are safely and effectively counseled, and all four genetic counseling goals are addressed. Areas of further research include diagnostic and reproductive genetic counseling/testing practices, evaluations of novel approaches to care, and the role and use of different health providers in practice.
\end{abstract}

Keywords Genetic counseling $\cdot$ Genetic testing $\cdot$ Neurodegenerative disease $\cdot$ Huntington's disease $\cdot$ Pre-symptomatic testing

\section{Introduction}

Patients with late-onset neurodegenerative diseases (LONDs, Box 1), and their at-risk relatives, face complex and challenging decisions when considering genetic testing [1]. Genetic

Ashley Crook

Ashley.K.Crook@student.uts.edu.au

Chris Jacobs

Chris.Jacobs@uts.edu.au

Toby Newton-John

Toby.Newton-John@uts.edu.au

Rosie O'Shea

Rosie.OShea@uts.edu.au

Alison McEwen

Alison.McEwen@uts.edu.au testing, through next-generation sequencing, is becoming more common in neurology clinics and allows multiple LOND genes to be screened concurrently at a lower cost and greater speed than ever before [2]. Genetic counseling facilitates and supports individuals through the process of decision-making

1 University of Technology Sydney, Graduate School of Health, Chippendale, Australia

2 Centre for MND Research, Department of Biomedical Science, Faculty of Medicine and Health Sciences, Macquarie University, Sydney, Australia

3 Department of Clinical Medicine, Faculty of Medicine and Health Sciences, Macquarie University, Sydney, Australia 
about testing [1]. Adequate knowledge and time allocated to provide genetic counseling are vital to maximize the health benefits of genetic testing while minimising harm to the client and their relatives $[1,3]$.

According to the Human Genetics Society of Australasia and the National Society of Genetic Counselors of the United States of America (USA), the activities of genetic counseling should integrate the following four goals:

1. Interpretation of family and medical histories to assess the chance of disease occurrence or recurrence $[4,5]$.

2. Education about the natural history of the condition, inheritance pattern, testing, management, prevention, support resources, and research $[4,5]$.

3. Counseling to promote informed choices in view of risk assessment, family goals, ethical and religious values [4-6].

4. Support to encourage the best possible adjustment to the disorder in an affected family member and/or to the risk of recurrence of that disorder [4, 6].

Genetic counselors are allied health professionals trained to provide this specialized care, however, the international shortage of genetic counselors requires other health providers to assume the role [7]. Health providers from outside of the specialty of genetics are often unprepared to integrate genetic and genomic health information into routine clinical care due to a lack of resources and guidelines, low confidence in initiating genetics discussions, and concerns about discrimination and psychological harm [8]. Guidelines and protocols for diagnostic, predictive, and reproductive genetic testing and associated counseling have been developed for a range of LONDs [9-15] and are informed by the Huntington's disease (HD) guidelines $[9,10,16,17]$. However, guidelines are not always translated into practice $[18,19]$. Examining contemporary genetic counseling practices for individuals undergoing diagnostic, predictive, and reproductive testing for LONDs is therefore important to understand whether these practices adequately address all four genetic counseling goals.

The primary aim of this review was to establish a comprehensive understanding of contemporary genetic counseling and testing practices for LONDs. The secondary aim was to identify the extent to which current practices address the established goals of genetic counseling. The findings will inform the development of updated genetic counseling and testing models of service delivery for LONDs and highlight future research priorities.

\section{Box 1 Definitions of key terms used in systematic review}

Genetic counseling: a communication process that aims to help individuals understand and adapt to the medical, psychological, familial, and reproductive implications of the genetic contribution to specific health conditions [4-6]. It integrates the four goals of (1) Interpretation of family and medical histories [4, 5], (2) Education about the condition $[4,5]$, (3) Counseling to promote informed choices, and (4) Support to encourage the best possible adjustment $[4,6]$. The term 'genetic counseling' here encompasses genetic counseling without genetic testing and genetic counseling provided both pre-, during and post-testing.

Diagnostic genetic testing: the initial search for pathogenic variants (mutations), often performed to confirm a diagnosis in a patient with symptoms consistent with the disease/ genetic condition. When a pathogenic variant is identified through diagnostic testing, predictive or reproductive testing becomes available to biological relatives.

Predictive (or pre-symptomatic) testing: a test performed to confirm whether an asymptomatic relative has inherited a pathogenic variant previously identified in a relative, which implies a future risk of developing the disease.

Reproductive testing: a test performed to prevent inheritance of a pathogenic variant through testing a pregnancy (prenatal diagnosis, and subsequent termination of pregnancy if the variant is confirmed) or in vitro fertilisation (IVF, pre-implantation genetic diagnosis). Individuals who do not wish to know their status as a pathogenic variant carrier may be able to undergo reproductive testing through exclusion or non-disclosure testing [85].

Late-onset neurodegenerative diseases (LONDs): for the purpose of this review, LONDs included mostly adult-onset, highly penetrant, and autosomal dominantly inherited neurodegenerative conditions. This included (but was not limited to) Huntington's disease, amyotrophic lateral sclerosis, frontotemporal dementia, Alzheimer's disease, genetic prion diseases, CADASIL (cerebral autosomal dominant arteriopathy with subcortical infarcts and leukoencephalopathy), muscular dystrophies, hereditary spastic paraplegias, spinocerebellar ataxias or neuropathies (including Charcot-Marie-Tooth disease and familial amyloid polyneuropathy). Each is expected to have similar potential psychological sequelae due to shared genetic and phenotypic characteristics. For example, all included LONDs are considered progressive and can affect movement, cognition, behavior, personality, or communication $[90,91]$. Although these LONDs (generally) have few treatments or preventative options available to stop or slow progression, individuals may 
use genetic testing results to plan their future, including undergoing reproductive testing. Genes associated with lower penetrance were excluded (e.g., APOE in Alzheimer's disease and all of the currently known Parkinson's disease genes), as were X-linked conditions (e.g., Duchenne or Becker muscular dystrophy, Kennedy's disease).

\section{Methods}

\section{Protocol and registration}

The systematic review protocol was registered on 01/20/2019 with the International Prospective Register of Systematic Reviews (PROSPERO, CRD42019121421). This review was guided by the Preferred Reporting Items for Systematic Reviews and Meta-Analyses (PRISMA) Statement [20] (Online resource 1).

\section{Eligibility criteria}

The inclusion and exclusion criteria are listed in Table 1 and were developed using the PICOS framework [20]. Only papers in English were included due to time and cost constraints. To highlight current practices used since the advent of next-generation sequencing technology, only papers published since 2009 were included. Additional key terms and justification for the eligibility criteria are outlined in Box 1. As we hoped to ascertain commonalities across the included LONDs, condition-specific aspects of genetic testing and counseling, such as anticipation in triplet repeat disorders or laboratory experiences, were not included.

\section{Literature search strategy}

Four electronic databases (CINAHL, MEDLINE, PsycINFO, and EMBASE) were searched using terms related to the target disease group, intervention, and publication dates (Online resource 2). Searches were combined and deduplicated using Endnote X9. Further references were elicited through backward-searching reference lists of included papers and forward-searching using Web of Science. The searches were re-run before the final analysis on 27 May 2020 .

\section{Study selection}

The primary (AC) and secondary reviewer (ROS) piloted the inclusion criteria. AC then screened all references against the criteria at the title and abstract and full-text screening stage, and ROS independently assessed $10 \%$ of titles and abstracts and $20 \%$ of full texts. Any disagreements were resolved through discussion. Where no agreement was

Table 1 Inclusion and exclusion criteria

\begin{tabular}{|c|c|}
\hline Inclusion & Exclusion \\
\hline \multicolumn{2}{|l|}{ Population } \\
\hline $\begin{array}{l}\text { Health providers of genetic testing and/or counseling for late-onset } \\
\text { neurodegenerative diseases (LONDs), OR }\end{array}$ & $\begin{array}{l}\text { Childhood-onset, lower penetrance, autosomal recessive or X-linked } \\
\text { inherited diseases }\end{array}$ \\
\hline $\begin{array}{l}\text { Adults with or at risk of a LOND or medical guardians of adults with } \\
\text { a LOND }\end{array}$ & $\begin{array}{l}\text { Included population not easily stratified from excluded population (e.g. } \\
\text { if there are multiple diseases or ages included) }\end{array}$ \\
\hline \multicolumn{2}{|l|}{ Intervention } \\
\hline $\begin{array}{l}\text { Any aspect of genetic counseling practice, both before, during, or after } \\
\text { genetic testing. This includes diagnostic testing, predictive or pre- } \\
\text { symptomatic testing, and reproductive testing }\end{array}$ & $\begin{array}{l}\text { Laboratory methods } \\
\text { Research genetic testing where the result is never disclosed to the } \\
\text { individual }\end{array}$ \\
\hline \multicolumn{2}{|l|}{ Comparator } \\
\hline \multicolumn{2}{|l|}{ No comparator } \\
\hline \multicolumn{2}{|l|}{ Outcomes } \\
\hline $\begin{array}{l}\text { Key components and activities of the genetic testing or counseling } \\
\text { process including the role and involvement of health providers }\end{array}$ & Outcomes not specific to the genetic counseling or testing process \\
\hline $\begin{array}{l}\text { Goals of genetic counseling or testing including experience, outcomes, } \\
\text { and recommendations that inform practice (Goals include any of the } \\
\text { four goals of genetic counseling: interpretation, education, coun- } \\
\text { seling, support) }\end{array}$ & $\begin{array}{l}\text { Likelihood of detecting a pathogenic variant, population frequencies, } \\
\text { phenotypic data, uptake rate of testing, and family communication, } \\
\text { without any information on clinical genetic testing or counseling } \\
\text { practices }\end{array}$ \\
\hline \multicolumn{2}{|l|}{ Study design and context } \\
\hline $\begin{array}{l}\text { Any method of peer-reviewed research, published after } 1 \text { January } \\
2009 \text {, in English, from worldwide }\end{array}$ & $\begin{array}{l}\text { Non-peer-reviewed papers, editorials, grey literature, non-systematic } \\
\text { reviews, book chapters or dissertations }\end{array}$ \\
\hline & $\begin{array}{l}\text { Practice recommendation or guideline papers that do not explicitly stem } \\
\text { from research or clinical experience }\end{array}$ \\
\hline
\end{tabular}


reached, the decision to include or exclude was made by a third reviewer (AM). Inter-rater reliability after title and abstract and full-text screening, respectively, demonstrated a level of agreement of $96.8 \%$ and $91.5 \%$, and at least strong agreement using the prevalence-adjusted bias-adjusted kappa (PABAK $=0.94$ and 0.83) $[21,22]$. The study selection process and reasons for exclusion are summarized in Fig. 1.

\section{Data extraction and quality assessment}

AC completed data extraction and critical appraisal forms for each included paper, then ROS verified and validated these. Data items were related to the research question (e.g. genetic testing type, health provider role and involvement, number of appointments, requirement of a support person, and activities involved) (Online resource 3 ). The activities involved in genetic counseling practice were extracted, grouped in key topic areas, and mapped against the four goals of genetic counseling [4-6].

The Qualsyst tool [23] was used to critically appraise the quality of included studies, as it allows for the assessment of quantitative and qualitative research across a broad range of study designs.

\section{Narrative synthesis}

A systematic narrative synthesis was performed to describe the variation between practices and activities [24]. A meta-analysis was not possible due to the heterogeneity of included studies. No papers were excluded based on a quality threshold, but the methodological quality and potential biases between and within studies were assessed.

\section{Results}

\section{Study characteristics and quality appraisal}

Sixty-eight papers representing 61 studies were included (Table 2; Online resource 3). Several studies focused on more than one condition, testing or study type. The most commonly studied condition was Huntington's disease (HD) (41/68), and the majority of papers focused on predictive testing (58/68) and used qualitative methods (24/68). There were no randomized control trials. The total number of included participants is not easily comparable between studies given the variability in study design, study population, outcomes, interventions, and settings. Sixty papers (60/68) achieved a Qualsyst score of 0.80 or higher, indicating sound methodological quality for their study type.

\section{Narrative synthesis: genetic counseling practices for LONDs}

Findings from the narrative synthesis are summarized under the following topics: the involvement and role of health
Fig. 1 Summary of the study selection process, as recommended by PRISMA [20]
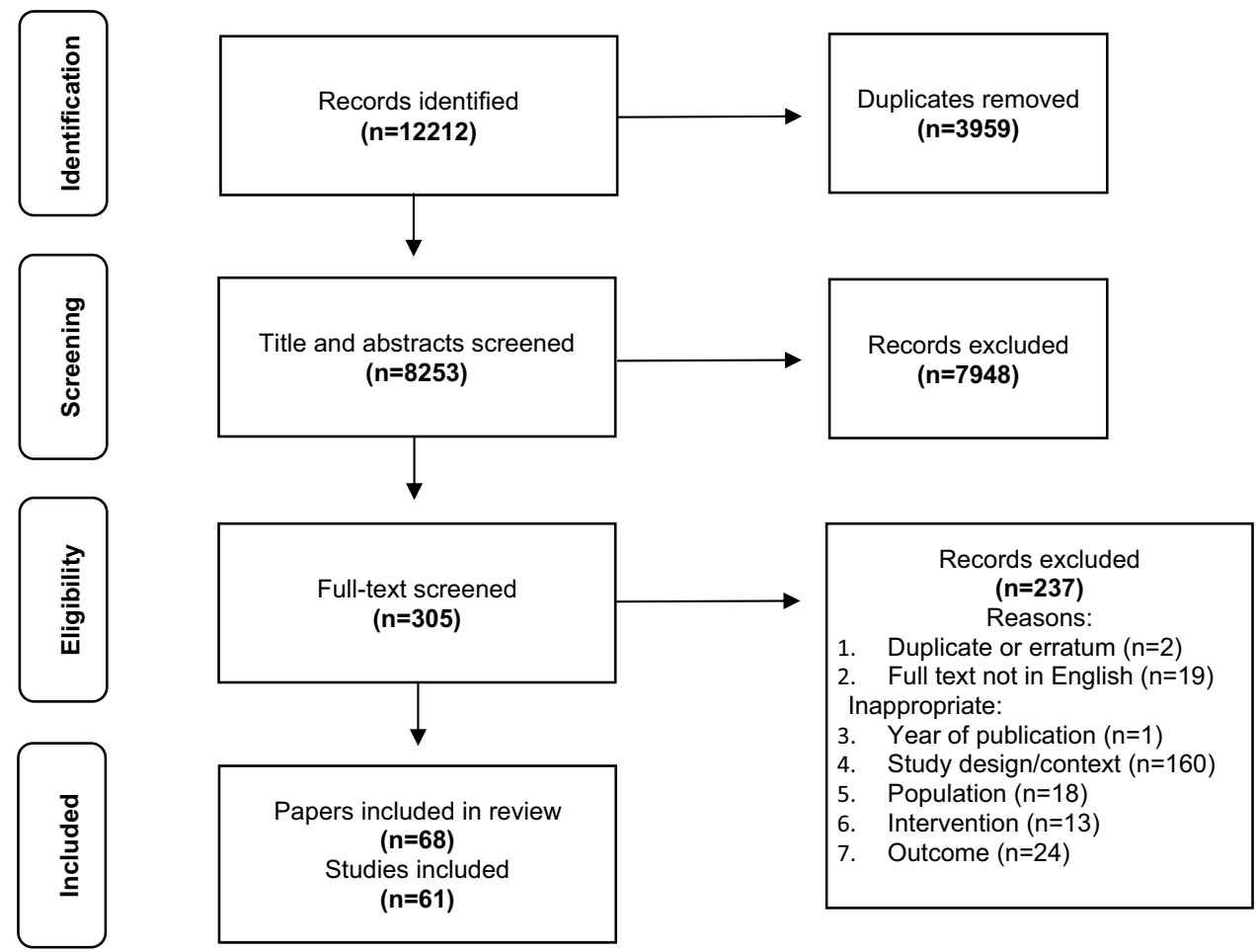
Table 2 Summary of included papers

\begin{tabular}{|c|c|c|c|}
\hline Characteristics & $\begin{array}{l}\text { Number } \\
\text { of papers }\end{array}$ & $\begin{array}{l}\text { Number } \\
\text { of studies }\end{array}$ & References \\
\hline \multicolumn{4}{|l|}{ Conditions investigated $^{a, b}$} \\
\hline Huntington's disease (HD) & 41 & 36 & $\begin{array}{l}{[25,26,28-37,40-43,46,47,49-51,53,55,56,58-61,64-68,70,73 \text {, }} \\
\text { 92-97] }\end{array}$ \\
\hline Spinocerebellar ataxias (SCAs- all subtypes) & 12 & 10 & {$[30,33,38,39,42-45,53,57,96,98]$} \\
\hline Amyotrophic lateral sclerosis/Frontotemporal dementia (ALS/FTD) & 11 & 10 & {$[52,55,59,63,71,72,74,75,82,99,100]$} \\
\hline Familial amyloid polyneuropathy (TTR-FAP) & 7 & 6 & {$[33,35,42,43,50,53,96]$} \\
\hline Unspecified disease type or included $>6$ LONDs & 5 & 5 & {$[48,76,89,101,102]$} \\
\hline Alzheimer's disease (AD) & 3 & 3 & {$[62,69,103]$} \\
\hline Prion disease & 2 & 2 & {$[54,104]$} \\
\hline $\begin{array}{l}\text { Cerebral autosomal dominant arteriopathy with subcortical infarcts } \\
\text { and leukoencephalopathy (CADASIL) }\end{array}$ & 2 & 2 & {$[27,33]$} \\
\hline Facioscapulohumeral muscular dystrophy (FSHD) & 1 & 1 & {$[105]$} \\
\hline \multicolumn{4}{|l|}{ Intervention type $e^{b}$} \\
\hline Diagnostic genetic testing & 17 & 17 & {$[25,37,54,59,61,62,68,70,72,74,75,93,99-101,103,105]$} \\
\hline Predictive genetic testing & 58 & 51 & $\begin{array}{l}{[25-28,30-33,35-50,52-57,59-71,73,74,76,89,92-97,99,100,} \\
\quad 102,104,105]\end{array}$ \\
\hline Reproductive genetic testing & 11 & 11 & {$[29,39,41,51,57,58,76,82,94,98,100]$} \\
\hline Unspecified genetic testing type & 1 & 1 & [34] \\
\hline \multicolumn{4}{|l|}{ Main author location $(s)^{b}$} \\
\hline Europe & 33 & 29 & $\begin{array}{l}{[26-28,30-33,35,38,42,44,46,48-51,53,56,58,60,61,63-66,74,} \\
\quad 75,89,94,96,99,101,104]\end{array}$ \\
\hline North America & 29 & 26 & $\begin{array}{l}{[25,29,34,36,37,39-41,45,47,52,54,55,57,59,62,68-73,82} \\
\quad 92,93,95,97,98,103]\end{array}$ \\
\hline South America & 2 & 2 & {$[43,44]$} \\
\hline Asia & 2 & 2 & {$[102,105]$} \\
\hline Africa & 1 & 1 & {$[67]$} \\
\hline Australia & 2 & 2 & {$[76,100]$} \\
\hline \multicolumn{4}{|l|}{ Source of genetic counseling practice } \\
\hline Practice sourced from clinical experience & 32 & 31 & $\begin{array}{l}{[27,29,33,38,39,41,44-46,49,54-59,62,63,67,68,70,72,74-} \\
\quad 76,94,97,99-102,105]\end{array}$ \\
\hline Practice trialed in clinical setting & 6 & 4 & {$[30,34,40,64-66]$} \\
\hline Practice recommended from clinical research & 20 & 16 & {$[26,28,31,32,35,36,42,43,50-53,60,71,89,92,95,96,103,104]$} \\
\hline Practice recommended from non-clinical research & 10 & 10 & {$[25,37,47,48,61,69,73,82,93,98]$} \\
\hline \multicolumn{4}{|l|}{ Study type $e^{b}$} \\
\hline Qualitative & 24 & 19 & $\begin{array}{l}{[25,26,28,36,37,42,47,51,53,56,60,61,64-66,69,71,73,82} \\
\quad 89,92,93,96,104]\end{array}$ \\
\hline Case series & 21 & 20 & $\begin{array}{l}{[27,30,39,41,43-45,49,52,55-57,63,67,70,94,96,101,103-} \\
105]\end{array}$ \\
\hline Cohort study & 14 & 14 & {$[27,31,33-36,38,40,43,46,50,58,60,95]$} \\
\hline Case study & 11 & 11 & {$[44,54,59,62,63,68,74-76,100,105]$} \\
\hline Cross-sectional survey & 9 & 9 & {$[29,32,69,72,73,97-99,102]$} \\
\hline Delphi survey & 1 & 1 & [48] \\
\hline Before and after study & 1 & 1 & {$[64]$} \\
\hline \multicolumn{4}{|l|}{ Risk of Bias assessment } \\
\hline$>0.90$ & 50 & 46 & $\begin{array}{l}{[25-35,37-45,48,50,51,53-55,57-59,61,64-66,68,70,72,74-76} \\
\quad 89,93-100,102,105]\end{array}$ \\
\hline $0.80-0.89$ & 10 & 10 & {$[36,46,60,62,67,69,71,73,82,101]$} \\
\hline $0.70-0.79$ & 5 & 5 & {$[47,49,52,92,103]$} \\
\hline $0.60-0.69$ & 1 & 1 & {$[56]$} \\
\hline $0.50-0.59$ & 2 & 2 & {$[63,104]$} \\
\hline
\end{tabular}

${ }^{a}$ Only data on conditions of interest extracted

${ }^{\mathrm{b}}$ Some papers included multiple categories 
providers, the testing protocol, barriers to accessing genetic counseling and testing, activities involved in genetic counseling practice, and addressing the goals of genetic counseling. Most of the results relate to predictive testing, but diagnostic and reproductive testing practices are reported where available.

\section{(i) The involvement and role of health providers}

A multidisciplinary team of two or more health providers was involved in the genetic counseling practice in 33 papers (Table 3). The specific role of each health provider within the team was not always clearly described, but 29 papers mentioned the role of neurologists, psychiatrists, and psychologists in assessing symptoms of disease or risk factors for coping. Five studies highlighted the need for increased training for those working in primary care [25-27], psychiatry [28, 29], and neurology [29]. The value of having certain providers in the team was formally evaluated in three studies [30-32]. In one study, most clients were satisfied with their neurologist appointment, particularly those who consulted a neurologist before, compared to after, receiving predictive testing results [32]. Although instruments to assess anxiety, depression, and other psychopathology informed risk of post-test distress [33-35], formal psychiatric testing provided more information than a questionnaire in one study [31]. In one practice trialed in a clinical setting, a psychologist or psychiatrist was involved in a clinical case conference where they never met the client but discussed the case in detail before testing and results disclosure [30]. This supported both the client and clinician throughout the predictive testing process [30].

(ii) The testing protocol

Up to four pre-testing appointments were required in some predictive testing protocols (Table 3). After testing, two studies recommended offering additional appointments to provide further education about the condition and discuss risk perception and beliefs [36, 37]. Sixteen studies encouraged the client to attend short or longer-term psychological follow-up sessions, either if a pathogenic variant was confirmed [26, 28, $38]$, regardless of the result [27, 30, 33, 39-48], or if requested or required based on pre-test discussions [46, $49,50]$. Acceptance of follow-up varied, with up to $80 \%$ of participants choosing to proceed with post-test psychological follow-up in two studies on predictive testing $[38,49]$, and none proceeding in two other studies in predictive [43] and reproductive testing [51].

In some practices, clients were required to complete structured psychological or psychosocial surveys [30, $31,33-35,40,43-45,50,52]$, or disease-specific neurological or objective knowledge measurement tools
$[30,53]$ in addition to, or instead of, a formal neurological or psychiatric/psychological assessment (Table 3). Health providers recommended deferring testing in some studies if high risk of future clinical distress [31, $33,35,41,43,45,46,52,54]$, problematic motivation $[31,49,54-56]$, or the absence of a support system $[31,52,54]$ were identified. One case series highlighted three situations where individuals still underwent predictive testing despite having high-risk psychopathology [55]. The testing process included close interaction with the clients' psychiatric care team, and the outcome was successful in two of three cases [55]. Where symptoms were identified as part of the neurological or psychiatric/psychological assessment, the response varied. Many teams proceeded with predictive testing if clients perceived themselves as asymptomatic $[28,30$, $41,43,44,46,57]$, while others excluded symptomatic individuals from their predictive testing protocol [45, 57]. In the one study that discussed neurological and psychological assessments in reproductive testing, a couple's request for IVF could be rejected if symptoms were present in a parent and the couple seemed unable to provide a stable home environment [58].

Variations regarding the requirement of a support person throughout the testing process were reported in 14 papers (Table 3). Some papers cautioned that the support person might require attention, support, or information, particularly if their first attendance is at the client's results appointment [25, 26, 28, 41, 51, 54]. One study suggested that support should not be sought from a relative who is having predictive testing concurrently, as this could create further anxiety [42]. A support person may also adopt the decision-making role, as described by one case study of a patient with ALS and a family history of HD, whose wife was given decision-making capacity regarding HD predictive testing given his terminal condition [59]. No included studies formally evaluated the effect of having a support person (or not).

In two studies, clients provided positive feedback about the counseling, support, and information received throughout the structured protocol $[33,46]$. However, negative feedback was provided in nine studies $[27,33$, $41-43,46,47,53,60]$. Some clients were deterred by the length, complexity, rigidity, or content of the protocol (including total duration and number of consultations, and whether a support person was mandatory) $[27,33,41-43,46,47,53,60]$, particularly if they had already decided to proceed with testing $[53,60]$. Others were concerned that the psychological assessments pre-testing were unnecessary or that testing would be withheld based on the clients' psychological state [33, $41,43,47]$. Consequently, fourteen papers suggested 
Table 3 Variations among genetic counseling and testing practices for LONDs

\begin{tabular}{|c|c|c|c|c|}
\hline \multirow[t]{2}{*}{ Aspects of genetic counseling practice } & \multirow{2}{*}{$\begin{array}{l}\text { Num- } \\
\text { ber of } \\
\text { papers }\end{array}$} & \multicolumn{3}{|c|}{ References for each testing type } \\
\hline & & Diagnostic testing & Predictive testing & Reproductive testing \\
\hline \multicolumn{5}{|l|}{ Health providers involved in the testing team } \\
\hline Neurologist & 24 & {$[70,72,75,101,105]$} & $\begin{array}{r}{[27,30,32,38,39,42,44-46,49,52,55} \\
57,59,60,67,70,71,75,95,102,105]\end{array}$ & [39] \\
\hline Geneticist & 23 & {$[75,101,105]$} & $\begin{array}{l}{[27,30,32,39,41,43-46,48,49,52,56} \\
\quad 60,63,67,71,102,104,105]\end{array}$ & {$[39,58]$} \\
\hline Psychologist & 21 & {$[75,101]$} & $\begin{array}{l}{[27,30,38-41,43-46,48,49,56,57,60} \\
\quad 63,67,102,104]\end{array}$ & {$[39]$} \\
\hline Genetic counselor & 15 & {$[70,72,105]$} & $\begin{array}{l}{[39-41,44,45,48,52,55,57,59,70,71} \\
102,105]\end{array}$ & {$[39]$} \\
\hline Psychiatrist & 7 & {$[70]$} & {$[30,31,44,49,55,70,102]$} & \\
\hline Nurse & 7 & {$[70,72]$} & {$[48,49,56,67,70,102]$} & \\
\hline Social worker & 6 & [72] & {$[39,44,48,49,55]$} & {$[39]$} \\
\hline Molecular biologist/ laboratory geneticist & 3 & & {$[30,48,49]$} & \\
\hline Family physician & 2 & & {$[30,57]$} & \\
\hline Medical doctor (other or unspecified) & 2 & & {$[39,48]$} & [39] \\
\hline Obstetrician/ gynaecologist & 2 & & & {$[41,58]$} \\
\hline Bioethicist & 1 & & [39] & [39] \\
\hline Neuropsychiatrist & 1 & [70] & {$[70]$} & \\
\hline \multicolumn{5}{|l|}{ Neurological assessment } \\
\hline Mandatory & 11 & {$[70]$} & {$[27,30,32,33,38,39,45,46,57,70,95]$} & \\
\hline As needed & 5 & & {$[41,43,44,49]$} & {$[58]$} \\
\hline Offered & 1 & & {$[32]$} & \\
\hline Where possible & 2 & & {$[40,47]$} & \\
\hline \multicolumn{5}{|l|}{ Psychiatric/ psychological assessments ${ }^{\mathrm{a}}$} \\
\hline Mandatory & 16 & & $\begin{array}{l}{[27,30,31,38,39,41-43,45,55-57,60} \\
\quad 63,89,104]\end{array}$ & \\
\hline As needed & 9 & & {$[35,41,43,44,49,52,54,71]$} & {$[58]$} \\
\hline \multicolumn{5}{|c|}{ Minimum recommended number of appointments } \\
\hline \multicolumn{5}{|l|}{ Pretest } \\
\hline 1 & 5 & [105] & {$[52,63,71,105]$} & {$[41]$} \\
\hline $1+$ reflection time & 3 & & {$[41,49,60]$} & \\
\hline 2 & 7 & & {$[30,40,42,44,46,47,56]$} & \\
\hline 3 & 4 & & {$[33,41,60,67]$} & \\
\hline 4 & 4 & & {$[27,38,43,44]$} & \\
\hline \multicolumn{5}{|l|}{ Post-test } \\
\hline 1 & 17 & {$[105]$} & {$[44,52,60,63,67,71,105]$} & \\
\hline $1+$ follow-up encouraged & 19 & & {$[26-28,30,33,36-48]$} & {$[51]$} \\
\hline \multicolumn{5}{|l|}{ Support person at appointments ${ }^{\mathrm{b}}$} \\
\hline At results appointment & 6 & & & {$[27,40,42-44,47]$} \\
\hline Strongly encouraged & 5 & {$[59,75]$} & & {$[41,42,47]$} \\
\hline Optional & 3 & & & {$[41,43,52]$} \\
\hline Involvement of both members of a couple & 3 & & & {$[57,58,82]$} \\
\hline Mandatory & 1 & & [44] & \\
\hline
\end{tabular}

${ }^{a}$ Psychological and psychiatric assessments have been combined as many studies were unclear about which health provider was involved ${ }^{\mathrm{b}}$ A support person may be a family member or peer

predictive testing be conducted in a more individual, flexible way by adapting the protocol to the specific needs, information processed and decision-making of the client [39, 40, 42, 44, 46-50, 57, 59, 61-63]. Adap- 
tations included reducing the number of appointments $[46,48,57,59,63]$, tailoring the content [46-48, 59, 63] or adapting the psychological support provided to each individual's needs [46, 50]. Still, no papers examined whether the number of pre- and post-test counseling sessions made a difference to outcomes. One UK series of studies trialed a new practice of support post-testing, with a novel standalone genetic counseling narrative group approach for individuals with a negative HD predictive test result [64] and a positive HD predictive test result $[65,66]$, as well as their partners [66]. The majority of participants were positive about the group session being a safe way to share experiences in a structured way [66], discuss difficult emotions, highlight coping resources, and feeling a sense of community [64, 65].

(iii) Barriers to accessing genetic counseling and testing

Ten studies described travel distance and time as barriers to accessing genetic counseling or testing $[33,42$, $43,47,59,62,67-70]$ or adequate support throughout the process [47]. Geographical barriers were addressed by conducting telephone or telehealth sessions as part of a regular protocol or depending on client preference [40, 41, 52, 58, 71, 72]. In other studies, home visits [68] or satellite clinics [70] were conducted, a local health provider was upskilled so that remote testing and counseling would be available [40, 47], or multiple appointments were arranged on the same day for one client [67] or multiple relatives [62, 68]. No adverse effects of these modifications were reported, but only two studies evaluated these practices [40,71].

Clients experienced difficulty accessing appropriate support or information in seven studies $[44,52,62$, 67-69, 73]. To address this barrier, educational materials were developed with the community in their preferred language $[62,67,73]$, clients were given funding support to attend appointments [67], and the team met with local physicians to educate about genetic risk and health resources [62]. No studies evaluated the differences in access to or uptake of testing before and after implementing these new practices. One educational website was piloted with at-risk individuals, health providers, and other stakeholders, and positive feedback was received [73].

Eight studies noted different laws were present that may be a barrier to accessing genetic counseling and testing. This included discrimination based on genetic testing results $[39,52]$, access to termination of pregnancy for genetic disorders [44, 57], access to direct, exclusion or non-disclosure reproductive testing [58] and obligations to inform relatives about genetic results or family medical information (before or after death) $[39,49,74,75]$.
Client-specific barriers to accessing predictive or reproductive testing included the presence of an intervening at-risk relative $[39,41,56,76]$ or where there were identical twins [39]. Three services explicitly excluded individuals at $25 \%$ risk from their predictive testing protocol if the intervening relative was available for testing [39, 44, 57]. Others used strategies to encourage relatives to consider testing, including suggesting the client discuss testing with their relative with the hope that they proceed first $[39,41,56,76]$; offering to meet the relative and counsel them regarding the consequences of the client having testing first [56]; or to undergo testing alongside their twin sibling [39]. These strategies were useful in two cases [39]. Where these strategies were unsuccessful, clients signed a confidentiality agreement to ensure nondisclosure (to maintain the intervening relative's right not to know) [39, 76]. To minimize adverse outcomes in a case where the intervening relative believed they would commit suicide if they knew they were affected, grandparental blood samples were also collected for use in reproductive testing before revealing the test outcome [76]. The possible adverse effect of testing clients at 25\% risk was highlighted in one study: of four intervening at-risk relatives who had been informed of their positive status, three became depressed, and one committed suicide after the result was disclosed [56].

(iv) Activities involved in genetic counseling practice

Thirty-five activities involved in contemporary genetic counseling and testing practices for LONDs are summarized in Table 4. Some activities only concerned certain types of genetic testing, while others were consistent across multiple testing settings. All reported activities were performed in one or more predictive testing practices (35/35), whereas fewer were reported in diagnostic (23/35) and reproductive testing (19/35).

(v) Addressing the goals of genetic counseling

Eighteen papers included activities that addressed all four goals of genetic counseling (Table 5). The interpretation goal was addressed in fewer than half of the papers (32/69). There were no major differences between the goals addressed and testing types, nor the health professionals involved or location of the practice.

\section{Discussion}

The primary aim of this systematic review was to establish a comprehensive understanding of contemporary genetic counseling and testing practices for LONDs. 


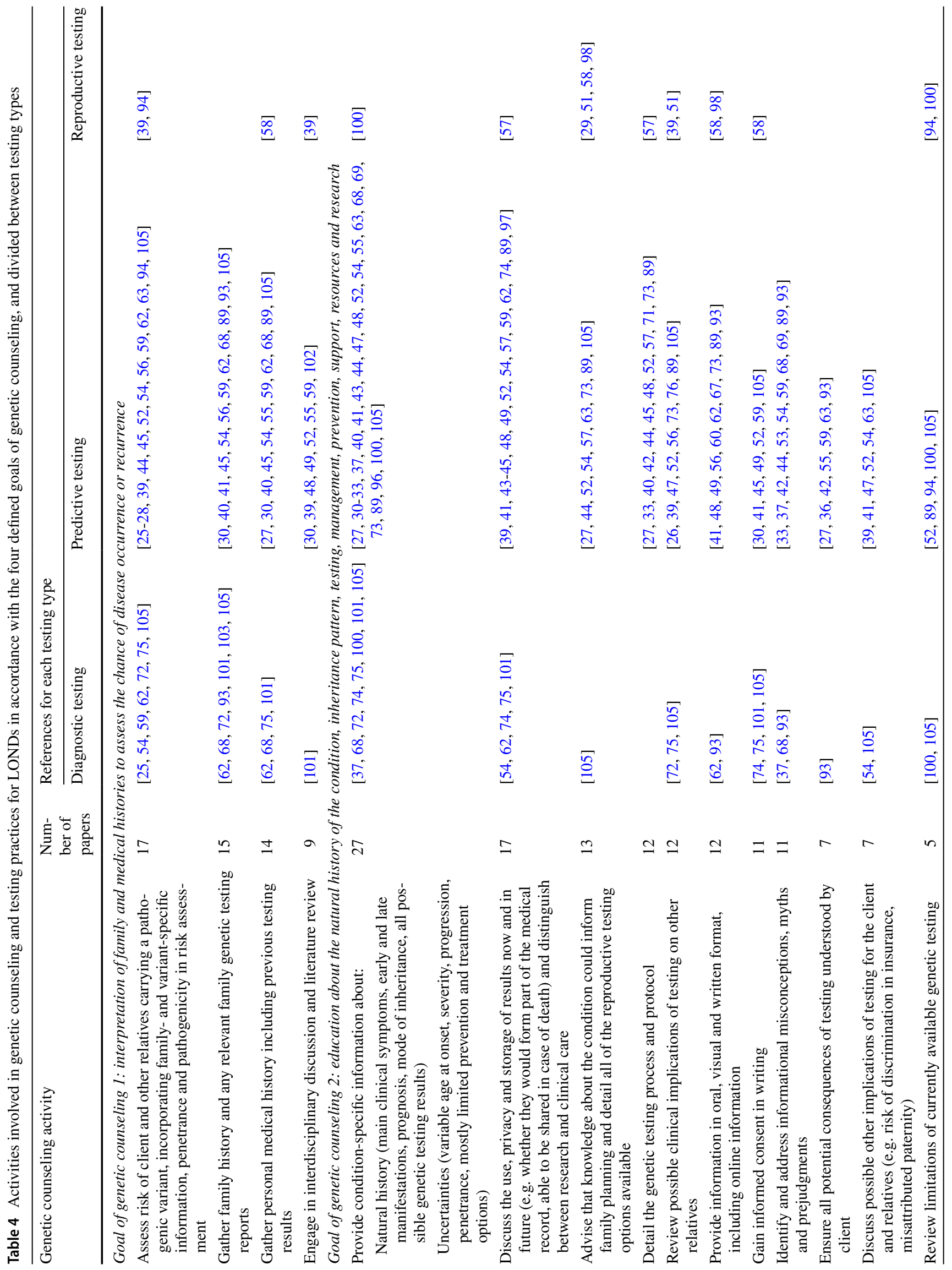




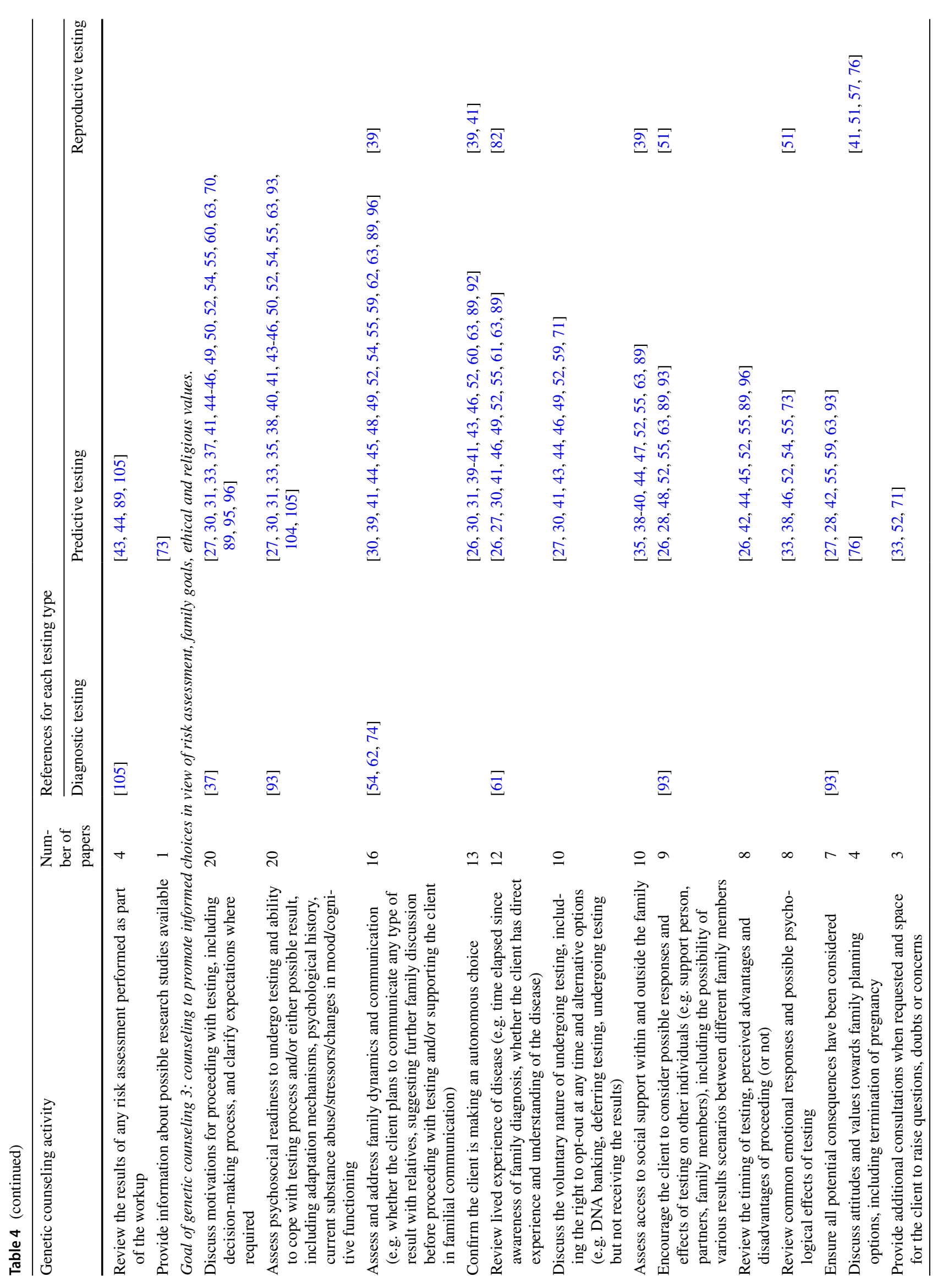




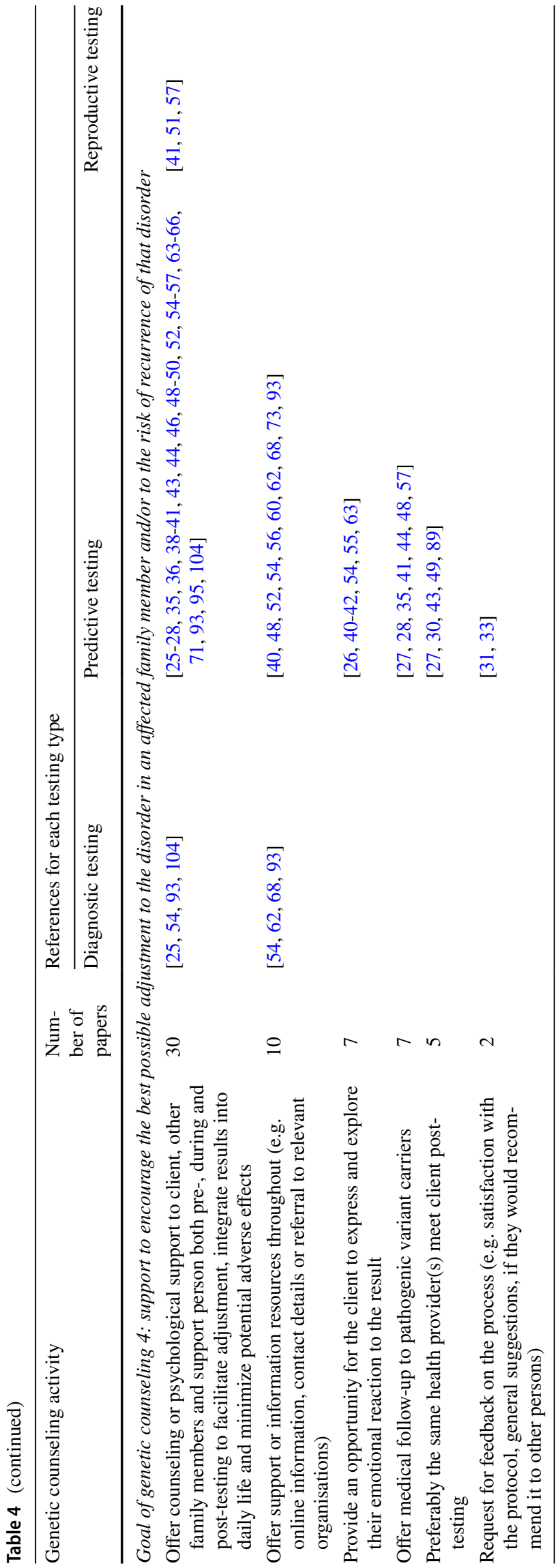

Sixty-one studies published in 68 papers from 19 countries that described genetic counseling and testing practices for LONDs since 2009 were included. Studies varied greatly in setting and design. HD was the most common condition studied, and predictive testing was examined more frequently than diagnostic or reproductive testing. Although some practices had shared aspects, there were many novel or inconsistent approaches to genetic counseling for LONDs. For predictive testing, a multidisciplinary care approach was taken in most studies, with neurologists, geneticists, and psychologists being the most common health providers involved. Health provider decision-making about genetic testing varied in the presence of ethical issues, high-risk psychopathology, and neurological symptoms. In some predictive testing protocols, up to four pre-test counseling sessions were required. Attendance at follow-up sessions posttesting was variable. Overall, there was an emerging focus on a client- or family-centered, flexible approach to genetic counseling for LONDs to address negative client feedback, possible harms, and barriers to accessing testing. However, few innovative modifications to practice were evaluated. The secondary aim was to identify the extent to which current practices address the established goals of genetic counseling. The findings indicate that current genetic counseling practices rarely address the four published genetic counseling goals.

Given most studies focused on predictive testing, it is difficult to draw any firm conclusions regarding genetic counseling practices for diagnostic and reproductive testing. There are several possible explanations for fewer studies in these two areas. In diagnostic testing, those undergoing testing will demonstrate some symptoms suggestive of a LOND. Therefore, both patients and their health providers may think a genetic test guides medical management and access to emerging targeted clinical trials [77, 78]. Despite this, as the diagnostic testing guidelines for HD note, the confirmation of a disease diagnosis may affect both the patient and their family [15]. Therefore, genetic counseling is an essential part of diagnostic testing. Depending on the patient and their family's needs and expectations, they may need to be informed of hereditary risks, assisted with adjusting to the diagnosis and familial risk or provided with access to predictive or reproductive testing, further support, information, and resources [15, 79]. One crucial difference between LONDs is that for entirely heritable conditions, like HD, a diagnosis would only be confirmed if a pathogenic variant was detected. For partially heritable conditions, like FTD, genetic testing may be performed separately to the diagnosis of the LOND [80]. Different genetic counseling practices would likely be required depending on the patient's diagnostic status and the likelihood of confirming a pathogenic variant $[14,15]$. The low number of studies on reproductive testing may be explained by its low uptake rate overall, as 
Table 5 Genetic counseling goals addressed in included studies

\begin{tabular}{|c|c|c|c|c|c|}
\hline \multirow[t]{2}{*}{ Characteristics } & \multirow{2}{*}{$\begin{array}{l}\text { Num- } \\
\text { ber of } \\
\text { papers }\end{array}$} & \multicolumn{4}{|l|}{ References for each testing type ${ }^{a}$} \\
\hline & & Diagnostic testing & Predictive testing & Reproductive testing & $\begin{array}{l}\text { Unspecified } \\
\text { testing type }\end{array}$ \\
\hline \multicolumn{6}{|c|}{ Goal of genetic counseling addressed in study ${ }^{a}$} \\
\hline Interpretation & 32 & $\begin{array}{l}{[25,54,59,62,68,70,72,75,93} \\
\quad 99-101,103,105]\end{array}$ & $\begin{array}{l}{[25,30,32,39-41,44,45,47-49} \\
52,54-57,59,62,68,70,76,89 \\
93,94,99,100,105]\end{array}$ & {$[39,41,57,58,76,94,100]$} & \\
\hline Education & 52 & $\begin{array}{l}{[25,37,54,62,68,70,72,74,75} \\
\quad 93,100,101,105]\end{array}$ & $\begin{array}{l}{[25-27,30-33,36,37,39-45,47-} \\
49,52-57,59,60,62,63,67-71 \\
73,74,76,89,93,94,96,97 \\
100,105]\end{array}$ & $\begin{array}{l}{[29,39,41,51,57,58,76,} \\
\quad 82,94,98,100]\end{array}$ & \\
\hline Counseling & 49 & {$[37,54,61,62,70,74,75,93,101]$} & $\begin{array}{c}{[26-28,30,31,33,35,37-50,52} \\
54-57,59-63,70,71,73,76,89 \\
92,93,95,96,102,104,105]\end{array}$ & {$[39,41,51,57,76,82]$} & [34] \\
\hline Support & 45 & {$[25,54,61,62,68,93,101]$} & $\begin{array}{l}{[25-28,30,31,33,35,36,38-50} \\
52,54-57,60-66,68,71,73,89 \\
93,95,102,104]\end{array}$ & {$[39,41,51,57]$} & {$[34]$} \\
\hline \multicolumn{6}{|c|}{ Number of goals of genetic counseling addressed in study ${ }^{a}$} \\
\hline 4 & 18 & {$[54,62,93,101]$} & $\begin{array}{l}{[30,39-41,44,45,47-49,52,54-} \\
57,62,89,93]\end{array}$ & {$[39,41,57]$} & \\
\hline 3 & 18 & {$[25,68,70,75]$} & $\begin{array}{l}{[25-27,31,33,42,43,59,60,63} \\
\quad 68,70,71,73,76,105]\end{array}$ & {$[51,76]$} & \\
\hline 2 & 21 & {$[37,61,72,74,100,105]$} & $\begin{array}{l}{[28,32,35-38,46,50,61,74,94-} \\
\quad 96,100,102,104]\end{array}$ & {$[58,82,94,100]$} & [34] \\
\hline 1 & 13 & {$[59,99,103]$} & {$[53,64-67,69,92,97,99]$} & {$[29,98]$} & \\
\hline
\end{tabular}

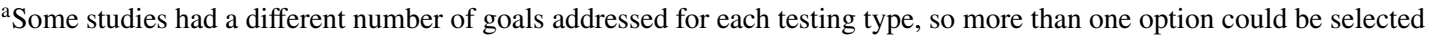

clients may choose other family planning options like conceiving naturally or choosing not to conceive [81, 82]. Legal barriers to accessing reproductive testing or termination of pregnancy in different regions $[44,57,58]$ may also explain the low uptake. Further investigation in both diagnostic and reproductive testing for LONDs is warranted.

The involvement of a multidisciplinary team was consistent across predictive testing practices, which is supported by the current guidelines $[9,11-14]$. The low number of studies including genetic counselors suggests this health professional group may be under-utilized. An explanation could be local barriers to incorporating genetic counselors in practice (health-care system disparities, cultural differences, or the global shortage of genetic counselors) [7, 83]. The involvement and role of different health providers were difficult to distinguish in many studies. Only three studies evaluated the benefits of neurologists, psychiatrists, or psychologists in a predictive testing team [30-32]. Where reported, neurological and psychiatric/psychological assessments in predictive testing were more commonly mandatory, which contrasts with the HD predictive testing guidelines, where these assessments are considered important but not required in a predictive testing protocol [9]. In the presence of high-risk psychopathology, neurological symptoms, or ethical issues in predictive testing, health provider decision-making about proceeding with testing varied. There was no apparent trend to suggest that responses differed between health provider specialty types. Further research is required to compare genetic counseling practices for LONDs between different health providers and assess whether this affects patient outcomes and testing decision-making.

Many studies highlighted the need for an individualized, flexible, client-centered approach to genetic counseling practice, given that a client who attends for genetic testing and counseling has a unique lived experience and motivation for proceeding with testing $[25,39,41,45,55,63,69,76,82]$. Practices should also consider the possible implications of genetic testing for the client's family, given the potential risk of harm for relatives [56, 76], and this is reflected in the current HD predictive testing protocol [9]. Financial, geographical, or language barriers to accessing testing or appropriate support and information may also need addressing [44, 52, $62,67-69,73]$. Therefore, clients may or may not require a neurological or psychological/psychiatric assessment, a support person at appointments, multiple pre- or post-testing consultations, or further resources, support, or information. Predictive testing performed within an integrated counseling protocol is considered safe in several studies, with few major adverse events reported in clients [46, 84, 85]. Pre-test discussions are thought to protect against adverse 
psychological effects post-testing [27, 41, 60]. Few included studies assessed the effectiveness and safety of a modified versus more traditional genetic counseling protocol, highlighting an area of necessary evaluation in the future that is supported by a previous quality assessment on genetic counseling for predictive testing of LONDs [86].

Of the studies that did assess innovative genetic counseling practices, there was evidence to support telephone or telehealth consultations for clients to access more flexible testing and support locally [40, 71]. In contrast, the predictive HD testing guidelines, published in 2013, state that results should never be given by telephone [9]. Perhaps this recommendation requires review, given emerging data on telehealth use during the COVID-19 pandemic [87, 88]. Health providers' time may become more limited if a clinical trial for asymptomatic patients becomes available, and interest in predictive testing increases [70, 89]. Still, some may decide not to be tested, as demonstrated by familial amyloid polyneuropathy [33], where disease-modifying therapies are already available, so non-directive counseling remains essential. Additional novel practices, such as using an educational website pre-testing [73] or group sessions post-testing [64-66], may also help manage health provider time. Other innovative approaches to genetic counseling practice should be considered and evaluated, with client safety at the forefront.

All genetic counseling activities were identified in one or more predictive testing studies. In comparison, less activities were identified in diagnostic and reproductive testing (although fewer studies were in these areas). The majority of current practices did not meet all four genetic counseling goals, suggesting that current practices do not reflect the required goals. It is also possible the goals need to be adapted to align with the specific practices required for LONDs. Findings do highlight knowledge gaps and considerations for further research in genetic counseling and testing for LONDs. The identified genetic counseling activities provide a basis for the requirements of a genetic counseling service delivery model for LONDs that addresses all four genetic counseling goals. This model will need to be customized to accommodate the client's specific needs and regional differences in providing care.

\section{Limitations}

Limitations exist regarding the individual articles and study selection methodology. The inclusion criteria resulted in the omission of works published in different languages, before 2009 and presented outside peer-reviewed journals. Consequently, no randomized control trials were identified, and eight low-quality studies were not excluded, affecting the robustness of the synthesis. LONDs were reported altogether due to their shared similarities, and therefore condition-specific issues were likely present but not extracted. In addition, studies from 19 countries were included, so there were likely regional differences between genetic counseling practices. Still, aside from the health providers involved and laws that impacted access to genetic counseling and testing, there were no clear country-specific differences.

Firm conclusions or implications for practice are premature, given the overall strength of evidence is low. Although several genetic counseling practices were identified, few were formally trialed or evaluated. There was considerable heterogeneity across the included studies in terms of study design, populations (and response rate), and outcomes. Practices were also inconsistently reported, and some study objectives assessed one aspect of genetic counseling practice only (e.g. knowledge, or motivations to undergo testing). The authors AC and ROS used their knowledge as experienced genetic counselors to combine and allocate genetic counseling activities amongst the four genetic counseling goals, which may have led to a bias toward presenting the aspects of practice considered important to a genetic counselor. Although included practices were assessed regarding addressing genetic counseling goals, it could not be definitively known whether certain practices omitted certain activities due to outcome reporting bias.

\section{Conclusion}

Contemporary genetic counseling and testing practices for LONDs reveal varied approaches informed by local laws, practices, and resources and the presence of different health providers. Few practices addressed all four goals of genetic counseling. A flexible, multidisciplinary approach to genetic counseling that is adaptable to the client and their family's needs continues to emerge. Evaluations of novel approaches to care are limited and provide an opportunity for further evaluation. Possible future study areas should focus on diagnostic and reproductive genetic testing and counseling practices, and the role and use of different health providers. As genetic testing becomes a routine part of care for patients with LONDs (and their relatives), health providers must balance their limited time and resources with ensuring that clients can be safely and effectively counseled, and all four genetic counseling goals are addressed. Increased involvement of genetic counselors or innovative approaches to providing genetic counseling may fulfill this need.

Supplementary Information The online version contains supplementary material available at https://doi.org/10.1007/s00415-021-10461-5. 
Acknowledgements Thank you to Ana Shah Hossaeni, information services librarian, who assisted with developing the search strategy.

Author contributions AC: study concept and design, major role in the acquisition of data, analysis and interpretation of data, and drafting and revision of the manuscript for content. CJ: study concept and design, revision of the manuscript for content. TN-J: study concept and design, revision of the manuscript for content. ROS: acquisition and analysis of data, revision of the manuscript for content. AME: study concept and design, acquisition and analysis of data, revision of the manuscript for content.

Funding A. Crook received funding for this project from the University of Technology Sydney Chancellors Research scholarship. C. Jacobs, T. Newton-John, R. O'Shea, and A. McEwen report no disclosures relevant to the manuscript.

Availability of data and materials Complete searches and data extraction tables are available in the supplementary information.

\section{Compliance with ethical standards}

Conflicts of interest On behalf of all authors, the corresponding author states that there is no conflict of interest.

\section{References}

1. Bird TD (1999) Risks and benefits of DNA testing for neurogenetic disorders. Semin Neurol 19(3):253-259. https://doi. org/10.1055/s-2008-1040841

2. Goldman JS, Van Deerlin VM (2018) Alzheimer's disease and frontotemporal dementia: the current state of genetics and genetic testing since the advent of next-generation sequencing. Mol Diagn Ther 22(5):505-513. https://doi.org/10.1007/s4029 1-018-0347-7

3. Patch C, Middleton A (2018) Genetic counselling in the era of genomic medicine. Br Med Bull 126(1):27-36. https://doi. org/10.1093/bmb/ldy008

4. Human Genetics Society of Australasia (2015) Guideline: Process of Genetic Counseling. Australia

5. Resta R, Biesecker BB, Bennett RL, Blum S, Estabrooks Hahn S, Strecker MN, Williams JL (2006) A new definition of genetic counseling: national society of genetic counselors' task force report. J Genet Couns 15(2):77-83. https://doi.org/10.1007/ s10897-005-9014-3

6. Ad Hoc Committee on Genetic Counseling ASoHG (1975) Genetic counseling. Am J Hum Gen 27(2):240-242

7. Ormond KE, Laurino MY, Barlow-Stewart K, Wessels TM, Macaulay S, Austin J, Middleton A (2018) Genetic counseling globally: where are we now? Am J Med Genet C Semin Med Genet 1:98-107

8. White S, Jacobs C, Phillips J (2020) Mainstreaming genetics and genomics: a systematic review of the barriers and facilitators for nurses and physicians in secondary and tertiary care. Genet Med 22:1149-1155. https://doi.org/10.1038/s41436-020-0785-6

9. MacLeod R, Tibben A, Frontali M, Evers-Kiebooms G, Jones A, Martinez-Descales A, Roos RA, Editorial C, Working Group "Genetic Testing Counselling" of the European Huntington Disease N (2013) Recommendations for the predictive genetic test in Huntington's disease. Clin Genet 83(3):221-231. https://doi. org/10.1111/j.1399-0004.2012.01900.x
10. Skirton H, Goldsmith L, Jackson L, Tibben A (2013) Quality in genetic counselling for presymptomatic testing-clinical guidelines for practice across the range of genetic conditions. Eur J Hum Genet 21(3):256-260. https://doi.org/10.1038/ ejhg.2012.174

11. Andersen PM, Abrahams S, Borasio GD, de Carvalho M, Chio A, Van Damme P, Hardiman O, Kollewe K, Morrison KE, Petri S, Pradat PF, Silani V, Tomik B, Wasner M, Weber M (2012) EFNS guidelines on the clinical management of amyotrophic lateral sclerosis (MALS) - revised report of an EFNS task force. Eur J Neurol 19(3):360-375. https://doi.org/10.111 1/j.1468-1331.2011.03501.x

12. Sorbi S, Hort J, Erkinjuntti T, Fladby T, Gainotti G, Gurvit H, Nacmias B, Pasquier F, Popescu BO, Rektorova I, Religa D, Rusina R, Rossor M, Schmidt R, Stefanova E, Warren JD, Scheltens P (2012) EFNS-ENS Guidelines on the diagnosis and management of disorders associated with dementia. Eur J Neurol 19(9):1159-1179. https://doi.org/10.111 1/j.1468-1331.2012.03784.x

13. Bocchetta M, Mega A, Bernardi L, Di Maria E, Benussi L, Binetti G, Borroni B, Colao R, Di Fede G, Fostinelli S (2016) genetic counseling and testing for Alzheimer's disease and frontotemporal lobar degeneration: an italian consensus protocol. J Alzheimers Dis 51(1):277-291

14. Goldman JS, Hahn SE, Catania JW, LaRusse-Eckert S, Butson MB, Rumbaugh M, Strecker MN, Roberts JS, Burke W, Mayeux R, Bird T, American College of Medical G, the National Society of Genetic C (2011) Genetic counseling and testing for Alzheimer disease: joint practice guidelines of the American College of Medical Genetics and the National Society of Genetic Counselors. Genet Med 13(6):597-605. https://doi.org/10.1097/ GIM.0b013e31821d69b8

15. Craufurd D, MacLeod R, Frontali M, Quarrell O, Bijlsma EK, Davis M, Hjermind LE, Lahiri N, Mandich P, Martinez A, Tibben A, Roos RA, Working Group on Genetic C, Testing of the European Huntington's Disease N (2015) Diagnostic genetic testing for Huntington's disease. Pract Neurol 15(1):80-84. https:// doi.org/10.1136/practneurol-2013-000790

16. International Huntington Association (IHA) and the World Federation of Neurology (WFN) Research Group on Huntington's Chorea (1994) Guidelines for the molecular genetics predictive test in Huntington's disease. Neurology 44(8):1533-1536

17. International Huntington Association (IHA) and the World Federation of Neurology (WFN) Research Group on Huntington's Chorea (1994) Guidelines for the molecular genetics predictive test in Huntington's disease. J Med Genet 31(7):555-559. https ://doi.org/10.1136/jmg.31.7.555

18. Grimshaw JM, Shirran L, Thomas R, Mowatt G, Fraser C, Bero L, Grilli R, Harvey E, Oxman A, O’Brien MA (2001) Changing provider behavior: an overview of systematic reviews of interventions. Med Care 39(8 Suppl 2):II2-II45

19. Grol R, Grimshaw J (2003) From best evidence to best practice: effective implementation of change in patients' care. Lancet 362(9391):1225-1230. https://doi.org/10.1016/s0140 -6736(03)14546-1

20. Moher D, Liberati A, Tetzlaff J, Altman DG (2009) Preferred reporting items for systematic reviews and meta-analyses: the PRISMA statement. Ann Intern Med 151(4):264-269

21. McHugh ML (2012) Interrater reliability: the kappa statistic. Biochem Med (Zagreb) 22(3):276-282

22. Byrt T, Bishop J, Carlin JB (1993) Bias, prevalence and kappa. J Clin Epidemiol 46(5):423-429. https://doi.org/10.1016/08954356(93)90018-V

23. Kmet LM, Lee RC, Research AHFfM, Cook LS (2004) Standard Quality Assessment Criteria for Evaluating primary research 
papers from a variety of fields. Alberta Heritage Foundation for Medical Research, Edmonton

24. Popay J, Roberts H, Sowden A, Petticrew M, Arai L, Rodgers M, Britten N, Roen K, Duffy S (2006) Guidance on the conduct of narrative synthesis in systematic reviews: a product from the ESRC methods programme (Version I). University of Lancaster, Lancaster, UK

25. Etchegary H (2011) Healthcare experiences of families affected by Huntington disease: need for improved care. Chronic IIln 7(3):225-238. https://doi.org/10.1177/1742395311403637

26. Andersson PL, Juth N, Petersen A, Graff C, Edberg A-K (2013) Ethical aspects of undergoing a predictive genetic testing for Huntington's disease. Nurs Ethics 20(2):189-199. https://doi. org/10.1177/0969733012452686

27. Reyes S, Kurtz A, Herve D, Tournier-Lasserve E, Chabriat H (2012) Presymptomatic genetic testing in CADASIL. J Neurol 259(10):2131-2136. https://doi.org/10.1007/s00415-012-6468-8

28. Andersson PL, Petersen A, Graff C, Edberg A-K (2016) Ethical aspects of a predictive test for Huntington's Disease: a long term perspective. Nurs Ethics 23(5):565-575. https://doi. org/10.1177/0969733015576356

29. Klitzman R, Abbate KJ, Chung WK, Ottman R, Leu C-S, Appelbaum PS (2014) Views of preimplantation genetic diagnosis among psychiatrists and neurologists. J Reprod Med 59(7-8):385-392

30. Mariotti C, Ferruta A, Gellera C, Nespolo C, Fancellu R, Genitrini S, Di Bella D, Panzeri M, Nanetti L, Tomasello C, Taroni F, Foresti G, Astori S (2010) Predictive genetic tests in neurodegenerative disorders: a methodological approach integrating psychological counseling for at-risk individuals and referring clinicians. Eur Neurol 64(1):33-41. https://doi. org/10.1159/000315033

31. Uhrova T, Zidovska J, Koblihova J, Klempir J, Majerova V, Roth J (2013) Importance of psychiatric examination in predictive genetic testing for Huntington disease. Neurol Neurochir Pol 47(6):534-541

32. Oosterloo M, Bijlsma EK, Verschuuren-Bemelmans CC, Schouten MI, de Die-Smulders C, Roos RAC (2020) Predictive genetic testing in Huntington's disease: should a neurologist be involved? Eur J Hum Genet 28:1205-1209. https://doi. org/10.1038/s41431-020-0633-9

33. Paneque M, Felix J, Mendes A, Lemos C, Ledo S, Silva J, Sequeiros J (2019) Twenty years of a pre-symptomatic testing protocol for late-onset neurological diseases in Portugal. Acta Med Port 32(4):295-304

34. Esplen MJ, Cappelli M, Wong J, Bottorff JL, Hunter J, Carroll J, Dorval M, Wilson B, Allanson J, Semotiuk K, Aronson M, Bordeleau L, Charlemagne N, Meschino W (2013) Development and validation of a brief screening instrument for psychosocial risk associated with genetic testing: a pan-Canadian cohort study. BMJ open 3:e002227. https://doi.org/10.1136/bmjopen-2012002227

35. Ledo S, Ramires A, Leite A, Dinis MAP, Sequeiros J (2018) Long-term predictors for psychological outcome of presymptomatic testing for late-onset neurological diseases. Eur J Med Genet 61(10):575-580. https://doi.org/10.1016/j. ejmg.2018.03.010

36. Stuttgen K, Dvoskin R, Bollinger J, McCague A, Shpritz B, Brandt J, Mathews D (2018) Risk perception before and after presymptomatic genetic testing for Huntington's disease: Not always what one might expect. Mol Genet Genomic Med 6(6):1140-1147. https://doi.org/10.1002/mgg3.494

37. Klitzman R (2010) Misunderstandings concerning genetics among patients confronting genetic disease. J Genet Couns 19(5):430-446. https://doi.org/10.1007/s10897-010-9307-z
38. Gonzalez C, Gomes E, Kazachkova N, Bettencourt C, Raposo M, Kay TT, MacLeod P, Vasconcelos J, Lima M (2012) Psychological well-being and family satisfaction levels five years after being confirmed as a carrier of the Machado-Joseph disease mutation. Genet Test Mol Biomarkers 16(12):1363-1368. https ://doi.org/10.1089/gtmb.2011.0370

39. Cruz Marino T, Reynaldo Arminan R, Cedeno HJ, Laffita Mesa JM, Gonzalez Zaldivar Y, Aguilera Rodriguez R, Velazquez Santos M, Almaguer Mederos LE, Paneque Herrera M, Velazquez Perez L (2011) Ethical dilemmas in genetic testing: examples from the Cuban program for predictive diagnosis of hereditary ataxias. J Genet Couns 20(3):241-248. https://doi.org/10.1007/ s10897-010-9347-4

40. Hawkins AK, Creighton S, Ho A, McManus B, Hayden MR (2013) Providing predictive testing for Huntington disease via telehealth: results of a pilot study in British Columbia, Canada. Clin Genet 84(1):60-64. https://doi.org/10.1111/cge.12033

41. Dufrasne S, Roy M, Galvez M, Rosenblatt DS (2011) Experience over fifteen years with a protocol for predictive testing for Huntington disease. Mol Genet Metab 102(4):494-504. https:// doi.org/10.1016/j.ymgme.2010.12.001

42. Guimaraes L, Sequeiros J, Skirton H, Paneque M (2013) What counts as effective genetic counselling for presymptomatic testing in late-onset disorders? A study of the consultand's perspective. J Genet Couns 22(4):437-447. https:// doi.org/10.1007/s10897-012-9561-3

43. Rodrigues CSM, de Oliveira VZ, Camargo G, Osorio CMdS, de Castilhos RM, Saraiva-Pereira ML, Schuler-Faccini L, Jardim LB (2012) Presymptomatic testing for neurogenetic diseases in Brazil: assessing who seeks and who follows through with testing. J Genet Couns 21(1):101-112. https://doi.org/10.1007/ s10897-011-9383-8

44. Schuler-Faccini L, Osorio CM, Romariz F, Paneque M, Sequeiros J, Jardim LB (2014) Genetic counseling and presymptomatic testing programs for Machado-Joseph Disease: lessons from Brazil and Portugal. Genet Mol Bio 37(1 Suppl):263-270

45. Cruz-Marino T, Velazquez-Perez L, Gonzalez-Zaldivar Y, Aguilera-Rodriguez R, Velazquez-Santos M, Vazquez-Mojena Y, Estupinan-Rodriguez A, Laffita-Mesa JM, ReynaldoArminan R, Almaguer-Mederos LE, Paneque M (2013) The Cuban program for predictive testing of SCA2: 11 years and 768 individuals to learn from. Clin Genet 83(6):518-524. https ://doi.org/10.1111/cge.12142

46. Mandich P, Lamp M, Gotta F, Gulli R, Iacometti A, Marchese R, Bellone E, Abbruzzese G, Ferrandes G (2017) 1993-2014: two decades of predictive testing for Huntington's disease at the Medical Genetics Unit of the University of Genoa. Mol Genet Genomic Med 5(5):473-480. https://doi.org/10.1002/ $\operatorname{mgg} 3.238$

47. Hawkins AK, Creighton S, Hayden MR (2013) When access is an issue: exploring barriers to predictive testing for Huntington disease in British Columbia, Canada. Eur J Hum Genet 21(2):148-153. https://doi.org/10.1038/ejhg.2012.147

48. Paneque M, Sequeiros J, Skirton H (2015) Quality issues concerning genetic counselling for presymptomatic testing: a European Delphi study. Eur J Hum Genet 23(11):1468-1472. https:// doi.org/10.1038/ejhg.2015.23

49. Clement S, Gargiulo M, Feingold J, Durr A (2015) Guidelines for presymptomatic testing for Huntington's disease: past, present and future in France. Revue Neurol (Paris) 171(6-7):572-580. https://doi.org/10.1016/j.neurol.2015.02.016

50. Lêdo S, Paneque M, Rocha J, Leite Â, Sequeiros J (2013) Predictive testing for two neurodegenerative disorders (FAP and HD): a psychological point of view. Open J Genet 3:270-279. https:// doi.org/10.4236/ojgen.2013.34030 
51. van Rij MC, de Die-Smulders CEM, Bijlsma EK, de Wert GMWR, Geraedts JP, Roos RAC, Tibben A (2013) Evaluation of exclusion prenatal and exclusion preimplantation genetic diagnosis for Huntington's disease in the Netherlands. Clin Genet 83(2):118-124. https://doi.org/10.1111/cge.12058

52. Benatar M, Stanislaw C, Reyes E, Hussain S, Cooley A, Fernandez MC, Dauphin DD, Michon S-C, Andersen PM, Wuu J (2016) Presymptomatic ALS genetic counseling and testing: Experience and recommendations. Neurology 86(24):2295-2302. https://doi. org/10.1212/WNL.0000000000002773

53. Leite A, Leite F, Dinis MAP (2017) Subjects at risk for genetic late-onset neurological diseases: objective knowledge. Public Health Genomics 20(3):158-165. https://doi.org/10.1159/00047 9292

54. Clift K, Guthrie K, Klee EW, Boczek N, Cousin M, Blackburn P, Atwal P (2016) Familial Creutzfeldt-Jakob Disease: case report and role of genetic counseling in post mortem testing. Prion 10(6):502-506

55. Goldman JS, Huey ED, Thorne DZ (2017) The confluence of psychiatric symptoms and neurodegenerative disease: impact on genetic counseling. J Genet Couns 26(3):435-441. https://doi. org/10.1007/s10897-016-0056-5

56. Bonnard A, Herson A, Gargiulo M, Durr A (2019) Reverse presymptomatic testing for Huntington disease: double disclosure when $25 \%$ at-risk children reveal the genetic status to their parent. Eur J Hum Genet 27(1):22-27. https://doi.org/10.1038/s4143 1-018-0255-7

57. Cruz-Marino T, Vazquez-Mojena Y, Velazquez-Perez L, Gonzalez-Zaldivar Y, Aguilera-Rodriguez R, Velazquez-Santos M, Estupinan-Rodriguez A, Laffita-Mesa JM, Almaguer-Mederos LE, Paneque M (2015) SCA2 predictive testing in Cuba: challenging concepts and protocol evolution. J Commun Genet 6(3):265-273. https://doi.org/10.1007/s12687-015-0226-4

58. Van Rij MC, De Rademaeker M, Moutou C, Dreesen JCFM, De Rycke M, Liebaers I, Geraedts JPM, De Die-Smulders CEM, Viville S, on behalf of the BruMaStra PGDwg (2012) Preimplantation genetic diagnosis (PGD) for Huntington's disease: the experience of three European centres. Eur J Hum Genet 20(4):368-375. https://doi.org/10.1038/ejhg.2011.202

59. Smith AL, Teener JW, Callaghan BC, Harrington J, Uhlmann WR (2014) Amyotrophic lateral sclerosis in a patient with a family history of Huntington disease: genetic counseling challenges. J Genet Couns 23(5):725-733. https://doi.org/10.1007/ s10897-014-9715-6

60. Ibisler A, Ocklenburg S, Stemmler S, Arning L, Epplen JT, Saft C, Hoffjan S (2017) Prospective evaluation of predictive DNA Testing for Huntington's Disease in a large German Center. J Genet Couns 26(5):1029-1040. https://doi.org/10.1007/s1089 7-017-0085-8

61. Hagen N (2018) The lived experience of Huntington's disease: a phenomenological perspective on genes, the body and the lived experience of a genetic disease. Health (London) 22(1):72-86. https://doi.org/10.1177/1363459316688516

62. Butler R, Dwosh E, Beattie BL, Guimond C, Lombera S, Brief E, Illes J, Sadovnick AD (2011) Genetic counseling for early-onset familial Alzheimer disease in large Aboriginal kindred from a remote community in British Columbia: unique challenges and possible solutions. J Genet Couns 20(2):136-142. https://doi. org/10.1007/s10897-010-9334-9

63. Riedijk SR, Niermeijer MFN, Dooijes D, Tibben A (2009) A decade of genetic counseling in frontotemporal dementia affected families: few counseling requests and much familial opposition to testing. J Genet Couns 18(4):350-356. https://doi.org/10.1007/ s10897-009-9222-3

64. MacLeod R, Moldovan R, Stopford C, Ferrer-Duch M (2018) Genetic counselling and narrative practices: a model of support following a "negative" predictive test for Huntington's Disease. J Huntingtons Dis 7(2):175-183. https://doi.org/10.3233/JHD170276

65. Spiers J, Smith JA, Ferrer-Duch M, Moldovan R, Roche J, MacLeod R (2020) Evaluating a genetic counseling narrative group session for people who have tested positive for the Huntington's disease expansion: an interpretative phenomenological analysis. J Genet Couns. https://doi.org/10.1002/jgc4.1229

66. Stopford C, Ferrer-Duch M, Moldovan R, MacLeod R (2020) Improving follow up after predictive testing in Huntington's disease: evaluating a genetic counselling narrative group session. J Commun Genet 11(1):47-58. https://doi.org/10.1007/s1268 7-019-00416-9

67. Futter MJ, Heckmann JM, Greenberg LJ (2009) Predictive testing for Huntington disease in a developing country. Clin Genet 75(1):92-97. https://doi.org/10.1111/j.1399-0004.2008.01044.x

68. Charles J, Lessey L, Rooney J, Prokop I, Yearwood K, Da Breo H, Rooney P, Walker RH, Sobering AK (2017) Presentation and care of a family with Huntington disease in a resource-limited community. J Clin Mov Disord 4(Article 4):1-8. https://doi. org/10.1186/s40734-017-0050-6

69. Withers M, Sayegh P, Rodriguez-Agudelo Y, Ernstrom K, Raman R, Montoya L, Zuno-Reyes A, Mosieri C, Matute E, Ringman JM (2019) A mixed-methods study of cultural beliefs about dementia and genetic testing among Mexicans and Mexican-Americans atrisk for autosomal dominant Alzheimer's disease. J Genet Couns 28(5):921-932. https://doi.org/10.1002/jgc4.1133

70. Bardakjian TM, Klapper J, Carey A, Wood J, Pauly M, Gasper K, Lawler K, Tran B, Bell Y, Zwil A, Gonzalez-Alegre P (2019) Addressing the value of multidisciplinary clinical care in Huntington's Disease: a snapshot of a new Huntington's Disease Center. J Huntingtons Dis 8(4):501-507. https://doi.org/10.3233/ JHD-190355

71. Fanos JH, Gronka S, Wuu J, Stanislaw C, Andersen PM, Benatar M (2011) Impact of presymptomatic genetic testing for familial amyotrophic lateral sclerosis. Genet Med 13(4):342-348. https ://doi.org/10.1097/GIM.0b013e318204d004

72. Klepek H, Nagaraja H, Goutman SA, Quick A, Kolb SJ, Roggenbuck J (2019) Lack of consensus in ALS genetic testing practices and divergent views between ALS clinicians and patients. Amyotroph Lateral Scler Frontotemporal Degener 20(3-4):216-221. https://doi.org/10.1080/21678421.2019.1582670

73. Hawkins Virani AKH, Creighton SM, Hayden MR (2013) Developing a comprehensive, effective patient-friendly website to enhance decision making in predictive testing for Huntington disease. Genet Med 15(6):466-472. https://doi.org/10.1038/ gim.2012.149

74. Mandich P, Mantero V, Verdiani S, Gotta F, Caponnetto C, Bellone E, Ferrandes G, Origone P (2015) Complexities of genetic counseling for ALS: a case of two siblings with discordant genetic test results. J Genet Couns 24(4):553-557. https://doi. org/10.1007/s10897-015-9831-y

75. Mantero V, Tarlarini C, Aliprandi A, Lauria G, Rigamonti A, Abate L, Origone P, Mandich P, Penco S, Salmaggi A (2017) Genetic counseling dilemmas for a patient with sporadic amyotrophic lateral sclerosis, frontotemporal degeneration and Parkinson's Disease. J Genet Couns 26(3):442-446. https://doi. org/10.1007/s10897-017-0088-5

76. Stark Z, Wallace J, Gillam L, Burgess M, Delatycki MB (2016) Predictive genetic testing for neurodegenerative conditions: how should conflicting interests within families be managed? J Med Ethics 42(10):640-642. https://doi.org/10.1136/medethics-2016103400

77. Ly CV, Miller TM (2018) Emerging antisense oligonucleotide and viral therapies for amyotrophic lateral sclerosis. Curr Opin 
Neurol 31(5):648-654. https://doi.org/10.1097/wco.0000000000 000594

78. Silva AC, Lobo DD, Martins IM, Lopes SM, Henriques C, Duarte SP, Dodart J-C, Nobre RJ, Pereira de Almeida L (2019) Antisense oligonucleotide therapeutics in neurodegenerative diseases: the case of polyglutamine disorders. Brain 143(2):407429. https://doi.org/10.1093/brain/awz328

79. Rothing M, Malterud K, Frich JC (2015) Family caregivers' views on coordination of care in Huntington's disease: a qualitative study. Scand J Caring Sci 29(4):803-809. https://doi. org/10.1111/scs.12212

80. Sieben A, Van Langenhove T, Engelborghs S, Martin JJ, Boon P, Cras P, De Deyn PP, Santens P, Van Broeckhoven C, Cruts $M$ (2012) The genetics and neuropathology of frontotemporal lobar degeneration. Acta Neuropathol 124(3):353-372. https:// doi.org/10.1007/s00401-012-1029-x

81. Decruyenaere M, Evers-Kiebooms G, Boogaerts A, Philippe K, Demyttenaere K, Dom R, Vandenberghe W, Fryns JP (2007) The complexity of reproductive decision-making in asymptomatic carriers of the Huntington mutation. Eur J Hum Genet 15(4):453-462. https://doi.org/10.1038/sj.ejhg.5201774

82. Hartzfeld DEH, Siddique N, Victorson D, O'Neill S, Kinsley L, Siddique T (2015) Reproductive decision-making among individuals at risk for familial amyotrophic lateral sclerosis. Amyotroph Lateral Scler Frontotemporal Degener 16(1-2):114-119. https://doi.org/10.3109/21678421.2014.951945

83. Skirton $\mathrm{H}$, Cordier $\mathrm{C}$, Ingvoldstad $\mathrm{C}$, Taris $\mathrm{N}$, Benjamin $\mathrm{C}$ (2015) The role of the genetic counsellor: a systematic review of research evidence. Eur J Hum Genet 23(4):452-458. https:// doi.org/10.1038/ejhg.2014.116

84. Almqvist EW, Bloch M, Brinkman R, Craufurd D, Hayden MR (1999) A worldwide assessment of the frequency of suicide, suicide attempts, or psychiatric hospitalization after predictive testing for Huntington disease. Am J Hum Gen 64(5):1293-1304. https://doi.org/10.1086/302374

85. Nance MA (2017) Genetic counseling and testing for Huntington's disease: a historical review. Am J Med Genet Part B Neuropsychiatr Genet 174(1):75-92. https://doi.org/10.1002/ ajmg.b.32453

86. Paneque M, Sequeiros J, Skirton H (2012) Quality assessment of genetic counseling process in the context of presymptomatic testing for late-onset disorders: a thematic analysis of three review articles. Genet Test Mol Biomarkers 16(1):36-45. https://doi. org $/ 10.1089 / \mathrm{gtmb} .2011 .0023$

87. Bloem BR, Dorsey ER, Okun MS (2020) The coronavirus disease 2019 crisis as catalyst for telemedicine for chronic neurological disorders. JAMA Neurol 77(8):927-928. https://doi. org/10.1001/jamaneurol.2020.1452

88. Rhoads S, Rakes AL (2020) Telehealth technology: reducing barriers for rural residents seeking genetic counseling. J Am Assoc Nurse Pract 32(3):190-192

89. Paneque M, Mendes A, Guimaraes L, Sequeiros J, Skirton H (2015) Genetics Health Professionals' views on quality of genetic counseling service provision for presymptomatic testing in lateonset neurological diseases in Portugal: core components, specific challenges and the need for assessment tools. J Genet Couns 24(4):616-625. https://doi.org/10.1007/s10897-014-9784-6

90. Hensman Moss DJ, Poulter M, Beck J, Hehir J, Polke JM, Campbell T, Adamson G, Mudanohwo E, McColgan P, Haworth A, Wild EJ, Sweeney MG, Houlden H, Mead S, Tabrizi SJ (2014) C9orf72 expansions are the most common genetic cause of Huntington disease phenocopies. Neurology 82(4):292-299. https:// doi.org/10.1212/wnl.0000000000000061

91. Wild EJ, Mudanohwo EE, Sweeney MG, Schneider SA, Beck J, Bhatia KP, Rossor MN, Davis MB, Tabrizi SJ (2008) Huntington's disease phenocopies are clinically and genetically heterogeneous. Mov Disord 23(5):716-720. https://doi. org/10.1002/mds.21915

92. Stuttgen KM, Bollinger JM, Dvoskin RL, McCague A, Shpritz B, Brandt J, Mathews DJH (2018) Perspectives on genetic testing and return of results from the first cohort of presymptomatically tested individuals at risk of Huntington Disease. J Genet Couns 27(6):1428-1437. https://doi.org/10.1007/s10897-018-0274-0

93. Schwartz RR (2010) Ripples from a stone skipping across the lake: a narrative approach to the meaning of Huntington's disease. J Neurosci Nurs 42(3):157-168

94. Tibben A, Dondorp WJ, de Wert GM, de Die-Smulders CE, Losekoot M, Bijlsma EK (2019) Risk assessment for Huntington's disease for (future) offspring requires offering preconceptional CAG analysis to both partners. J Huntingtons Dis 8(1):7178. https://doi.org/10.3233/JHD-180314

95. Quaid KA, Eberly SW, Kayson-Rubin E, Oakes D, Shoulson I, Huntington Study Group PI, Coordinators (2017) Factors related to genetic testing in adults at risk for Huntington disease: the prospective Huntington at-risk observational study (PHAROS). Clin Genet 91(6):824-831. https://doi.org/10.1111/cge.12893

96. Leite Â, Dinis MAP, Sequeiros J, Paúl C (2017) Motivation to perform presymptomatic testing in Portuguese subjects at-risk for late-onset genetic diseases. Interdisciplinaria 34(1):125-140

97. Eno CC, Barton SK, Dorrani N, Cederbaum SD, Deignan JL, Grody WW (2020) Confidential genetic testing and electronic health records: a survey of current practices among Huntington disease testing centers. Mol Genet Genomic Med 8(1):e1026. https://doi.org/10.1002/mgg3.1026

98. Cahn S, Rosen A, Wilmot G (2020) Spinocerebellar ataxia patient perceptions regarding reproductive options. Mov Disord Clin Pract 7(1):37-44. https://doi.org/10.1002/mdc3.12859

99. Vajda A, McLaughlin RL, Heverin M, Thorpe O, Abrahams S, Al-Chalabi A, Hardiman O (2017) Genetic testing in ALS: a survey of current practices. Neurology 88(10):991-999. https:// doi.org/10.1212/WNL.0000000000003686

100. Crook A, McEwen A, Fifita JA, Zhang K, Kwok JB, Halliday G, Blair IP, Rowe DB (2019) The C9orf72 hexanucleotide repeat expansion presents a challenge for testing laboratories and genetic counseling. Amyotroph Lateral Scler Frontotemporal Degener 20(5-6):310-316. https://doi.org/10.1080/21678 421.2019.1588904

101. Olszewska DA, McVeigh T, Fallon EM, Pastores GM, Lynch T (2018) The benefits of a neurogenetics clinic in an adult Academic Teaching Hospital. Ir J Med Sci 187(4):1073-1076. https ://doi.org/10.1007/s11845-018-1784-3

102. Tanaka K, Sekijima Y, Yoshida K, Tamai M, Kosho T, Sakurai A, Wakui K, Ikeda S-i, Fukushima Y (2013) Follow-up nationwide survey on predictive genetic testing for late-onset hereditary neurological diseases in Japan. J Hum Genet 58(8):560-563. https:// doi.org/10.1038/jhg.2013.34

103. Alexander ELR, Butler RK, Guimond C, Butler B, Sadovnick AD (2011) Accuracy of reported family history and effectiveness of medical record requests in genetic counseling for Alzheimer disease. J Genet Couns 20(2):129-135. https://doi.org/10.1007/ s10897-010-9330-0

104. Schwartz M, Brandel JP, Babonneau ML, Boucher C, Schaerer E, Haik S, Laplanche JL, Gargiulo M, Durr A (2019) Genetic testing in prion disease: psychological consequences of the decisions to know or not to know. Front Genet 10(Article 895):1-8. https ://doi.org/10.3389/fgene.2019.00895

105. Yanoov-Sharav M, Leshinsky-Silver E, Cohen S, Vinkler C, Michelson M, Lerman-Sagie T, Ginzberg M, Sadeh M, Lev D (2012) Genetic counseling and testing for FSHD (facioscapulohumeral muscular dystrophy) in the Israeli population. J Genet Couns 21(4):557-563. https://doi.org/10.1007/s1089 7-011-9422-5 